\title{
Forming Social Justice Projects: Student Activists Reflect on Coalition-Building
}

Darren E. Lund

University of Calgary

\begin{abstract}
Student activists share their experiences with racism and more specifically, their attempts to form school diversity initiatives. The author outlines a problematic lack of engagement of student activists in the scholarly literature on social justice, particularly related to their undervalued role as leaders in school-based antiracist coalitions. Excerpts from in-depth interviews with seven student participants in western Canadian schools offer new understandings on the potential of school-based activists. They explain the challenges and successes in building and sustaining activist coalitions and in pursuing their social justice efforts beyond school. Their contributions represent new voices to join the ongoing conversation in educational research and community activism.
\end{abstract}

Never doubt that a small, group of thoughtful, committed citizens can change the world. Indeed, it is the only thing that ever has. (Margaret Mead)

School activists who work to counter discrimination in the context of contemporary public schools face a number of challenges, particularly in light of the current backlash toward diversity initiatives. Seeking a link between the theoretical literature and the lived experience of actual student activists, this study was conducted to understand the workings of school-based initiatives designed to challenge racism and other forms of discrimination. The present study was designed to gain a clearer understanding of the realities of the activist

Darren E. Lund (dlund@ucalgary.ca) is an Assistant Professor in the Faculty of Education at the University of Calgary. His Ph.D. research on social justice activist coalitions was recognized with the AERA 2002 Outstanding Dissertation Award for Division B, Curriculum Studies. 
work of a small number of students in schools in western Canada. Among other research questions, the researcher sought to learn more about how they viewed their own activism as fostering coalition-building beyond their school experiences.

Conducting school research around issues of social justice requires a theoretical stance that seeks intersections across issues of "race," ethnicity, class, gender, sexual orientation, and other elements of social identity (e.g., $\mathrm{Ng}$, 2003). Hall's (1992) recognition of "race" as a social construction acknowledges the racialized context of contemporary schooling. The researcher intentionally positioned this research itself as a vehicle for both evaluating and facilitating social justice activism, and an instrument of community building among school activists. During the data gathering and analysis phases, regular contact between the researcher and participants allowed the reciprocal sharing of readings, resources, and guidance on social justice activism.

The research literature includes relatively few detailed analyses of student social action projects in Canadian schools, aside from anecdotal summaries of a small number of particular programs or activities (e.g., Berlin \& Alladin, 1996; Smith \& Young, 1996). Over nearly two decades of activism, the researcher has been made aware of numerous collective student initiatives in schools across Canada that tackle social justice issues. The lack of academic attention to successful school-based activist programs suggests that their efforts are either undiscovered or undervalued by the research community. In either case, the present study has taken steps to learn more from the students themselves and thereby to illustrate the benefits of a respectful engagement with activists in the educational community.

Students are rarely engaged in meaningful ways in educational research on social justice. Simply including students in discussions, as subjects of research projects, or as informants in surveys, is not a genuine means of engagement. In fact, these approaches may be viewed as cynical strategies by those in power, designed to falsely justify particular programming or policy changes. Another important acknowledgement needs to be made here that meaningful activist work very likely goes on in schools that remains distanced from university researchers' agendas and hence undiscovered.

Eliciting students' equitable participation in studies of social justice pedagogy more appropriately answers the call of other Canadian activists (e.g., Dei, James, James-Wilson, Karumanchery, \& Zine, 2000) to find meaningful ways of engaging them in bringing about change in schools and communities. For all of the inherent challenges, authentic collaborations between researchers and school activists hold tremendous potential for enacting progressive school change toward equity and fairness. The intentional engagement of young 
activists as respected participants in this research acknowledges their significant roles as leaders and valued informants in this area. Further, earlier reports on findings from this study also address what Giroux (1996) has identified as a growing conservative backlash toward "youth" culture in general (see Lund, 2001).

\section{Initial Guiding Assumptions and Hypothesis}

As a long-time activist and educator in this field, the researcher posited that ongoing projects would provide students with agency and a legitimate avenue to address diversity issues, tap into current community concerns, and provide ongoing opportunities for dialogue, debate, and consensus-building among the participants. Exploring a wide range of concerns and issues around specific activities in schools, this study focused on particular expectations, framed as a set of "guiding hypotheses" that Marshall and Rossman (1995) describe as "tools used to generate questions and to search for patterns" (p. 37). One hypothesis was that students' activism in school-based coalitions would lead to further activism and political engagement in their lives outside the school, and that involvement in this research would extend their sharing and networkbuilding. Many of the activists interviewed had already been involved in social issues in their communities for some time before they took on the work of coalition-building in their school settings. Past experiences with forming an activist group early in the researcher's teaching career strongly suggested that activist efforts in schools might further encourage students' long-term commitments to social justice.

\section{Students Engaging in Collaborative Action}

During the researcher's first year of teaching high school in Alberta, a rowdy group of students in a non-academic English class initiated the formation of Students and Teachers Opposing Prejudice (STOP). It has remained a popular school program and has been widely recognized for its innovative approaches to challenging racism and other forms of discrimination (e.g., Alberta Human Rights and Citizenship Commission, 2000; Canadian Race Relations Foundation, 2001). The students were excited when the US activist rock group, "Rage Against the Machine," named the STOP program "Freedom Fighter of the Month" in March, 2000.

STOP was formed in the potentially volatile social context of a region of Canada better known for extremist activity promoting racism (Kinsella, 2001), but has managed to recruit students, teachers, parents, administration, 
other school staff, government, media, and community agencies in a collective undertaking to challenge barriers to social justice. Activities have included awareness campaigns on violence against women, Tibetan independence, environmental concerns in Nigeria, First Nations issues in Canada, the rights of children, and Alberta's human rights policies. Specific student and teacher activism has entailed interrogation of school policies and curriculum materials, presentations to government officials, drama presentations to children, organizing local protests, international human rights advocacy, and public debates with political leaders on government policies (see Lund, 1998).

Over the past 16 years, several former STOP members have won recognition and awards for their exemplary community service and citizenship while working on projects for STOP. Numerous others have graduated to accept positions in international service agencies such as the UN and the Red Cross, with many former student activists continuing their work with human rights groups and social agencies as adults. Some former STOP student activists are engaged in related pursuits including teaching elementary school, nursing, social work, musical benefit concert promotion, and graduate studies in gender issues.

\section{Engaging Students in Collaborative Research}

An intention for the present study, reported in greater detail elsewhere (Lund, 2001) was to interview student activists engaged in social justice and diversity projects in their schools and communities around Alberta. Activists were identified using a "community nomination" method of selection, following the work of Foster (1993). Located through a network of teacher colleagues, professional associations, and community activists, participants in this research included seven students whose length of experience in this field ranged from one to five years. They lived in rural, smaller urban, and large urban settings, and came from a variety of ethnocultural backgrounds, as described briefly below. Their ethnic and geographic locations undoubtedly shape and inform their contributions, both as noted below and in complex ways to be explored in future analysis and research.

Semi-structured interviews took place over a period of about two years, and included site visits and at least two hours of in-depth conversation with each participant; these were tape-recorded, transcribed, and brought back to the participants for validation or revision for accuracy. Few changes were made to the original transcripts besides some minor corrections for clarity and grammatical correctness. Transcripts and other data were coded and analyzed 
for embodied meaning and subjected to validity requirements as outlined by Carspecken (1996).

\section{Participating Student Activists}

Lisa $^{1}$ was in grade 11 at a large Catholic high school in a smaller urban setting in the province. She was not yet active with an organized student club, but was taking steps to form a program to address diversity issues in her school. She and other friends sought permission from their school to promote a community awareness project on diversity. Lisa was white, Catholic, and 16 years old at the time of our interview. She was interviewed in the cafeteria of her school.

Sina is a Muslim of Indo-Canadian background who was in grade 12 in a diverse high school in a large urban centre. She noted that she often faced discrimination based on religious stereotyping, commenting that "when I tell people that I'm Muslim they automatically think that I' $m$ from Arabia and that I'm a terrorist.". She had been active in the school's annual participation in a regional student diversity leadership camp, was President of the school's Student Council, and also tutored non-English speaking students. We spoke at a coffee shop near her high school.

Sabrina and Ramona are sisters who were in grades 10 and 11, respectively, and both were active in their high school in a large urban centre. They were involved in an enriched academic program and both had taken on leadership roles in their school. Of Asian ancestry, they were fluently bilingual and both expected to attend university after graduation from high school. Ramona coordinated the school's Amnesty International chapter for two years. Sabrina was the student leader of another school club that also addresses social justice concerns. Both have also been actively involved in other local organizations that address poverty, human rights, and other social issues. I interviewed them separately in a foyer at the university near their high school.

Daria was in grade 12 in a large and diverse high school in a large urban centre, and identified herself as Latina of South American origins. She was born outside Canada and said her immigrant status shaped her experiences in the area of addressing diversity issues. Together with Steve and Jason, below, she helped form a student action group across three high schools. They met weekly and organized a variety of activities to educate other young people on the benefits of diversity and the dangers of discrimination. We spoke after school and the only available space was in her principal's office. She eagerly took his seat and I interviewed her from a small chair in front of the large desk,

1. All of the names of participants mentioned here are pseudonyms.

2. Readers should note that these interviews took place before the events of September 11, 2001. 
creating an interesting and symbolic rearrangement of the traditional researcher role.

Jason was also in grade 12 but attended a small urban high school. He described himself as a fairly average, mainstream guy. He and two of his friends, Steve and Daria, organized a program to challenge racism and other discrimination. The group received some favourable recognition from the media and a government agency, and at the time of the interviews, was organizing presentations to schools in their region.

Steve was also in grade 12. I interviewed him and Jason after an educational conference at which they had co-presented a session to teachers on taking action against racism with students. Both are of Anglo-Saxon origins, 17 years old at the time of the interviews, and both were in an academic school program with expectations of university attendance following graduation.

\section{Voices from the Student Activists}

For the students who are relatively new to activism, participation in schoolbased social action is gradually becoming an important part of their lives. ${ }^{3}$ Lisa explains that she was initially drawn into social justice activism by the experience of her father's becoming paraplegic in recent years. Watching her father face a number of physical and attitudinal barriers in society has helped to strengthen Lisa's resolve to assist in the struggle for social justice for disadvantaged or marginalized groups. "That happened about five years ago," she says, "and it probably did have something to do with [my interest in this area], because I can see how people treat disabled people differently." She has become sensitized to seeing the world through the eyes of another person who faces serious challenges on a regular basis, and believes this to be a catalyst in her wishing to form a group to fight discrimination of various types.

Lisa's desire to act on her sense of justice began with a strong role model; she admires that, "everywhere we would go, if it isn't wheelchair accessible or there aren't parking spots, my father will go in and just ask all these questions and often ask, 'Don't you people know anything?' and it's just pretty funny. Like we've even gone to the police station and got people ticketed for parking in handicapped spots!" Her admiration of the fighting spirit of her parent has inspired her own wish to take on issues that others in her school might simply ignore.

Even while in junior high school, Lisa had been involved in a "Justice and Peace" group sponsored by one of her teachers, but she expresses

3. The author uses the present tense in this section to enhance the immediacy of the participants' voices. 
disappointment that "we didn't do a lot globally. It was more making breakfasts for the kids-that kind of thing." Her wish to help others was fueled when she learned of antiracist activism taking place in her community that had been organized by some other young people, and she wanted to "kick-start" something similar at her school. So far, the only thing her school had done officially in the area of social justice was in response to a visit from Craig Kielburger, who was promoting his "Free the Children" movement (see Kielburger \& Major, 1998), seeking to liberate young people around the world from sweat shops and other exploitation. Lisa comments that "when Craig Kielburger came, about five students shaved their heads and raised money," but expresses frustration that momentum failed to build after his visit: "I thought there might have been a little bit more inspiration after the kids shaved their heads." She speculates that "maybe if we kind of related that [awareness] into other issues it might raise some awareness." Although her efforts to do so have not yet resulted in the successful formation of a lasting group at her school, she remains interested in social justice issues and in working collectively with others to confront injustice. She says, "For myself, a lot of the women's rights issues interest me, like what's currently going on in Afghanistan and Indonesia. I'm very interested in that personally, but we could probably build up to tackling things like that in our group." Lisa acknowledges another hurdle, namely that her fellow student activists first need to be educated on international issues of gender discrimination of which they are unaware, "because everyone has to know what they're supporting."

When asked if her experiences trying to organize a school-based coalition might lead her to further engagement outside her school, Lisa says that her wish to form a student group to challenge racism and sexism is fueled by a desire to "promote societal change," and that she expects to become a teacher after graduating from high school. She plans to keep these issues in the forefront of her own teaching, and is inspired by a woman she knows who "has taught in Africa; I'm interested in doing that." She anticipates being involved in social justice work somehow as an adult, and remarks that, as a member of the Canadian mainstream culture, "It's really hard to stay motivated. And then something will set you off, you'll see something on the news or you'll read something and you'll be like, 'Oh, I've got to get back to doing that."'

Lisa says she values cooperation in her activism, and wants to communicate directly with other students already in activist school groups. She speculates, "I was thinking if we did a joint thing with STOP or one of the other groups, our students would get an idea of what it's all about, and then we could try to start something here." She says she values the potential for peer influence and the benefits of having young people share ideas together. Her goal is to 
begin with small initiatives in her school, and then "do a little bit of work with students in other schools." Lisa has heard of the STOP group's annual Holocaust Awareness Symposium and says, "I want to be a part of that; I think that's really important."

Building on the successes of other programs seems a sensible way to start, with a greater chance of achieving results in the early stages of a group's formation. This interview allows her to explore some of these partnership ideas aloud, and to start plans to have interested activist students learning directly from each other. Lisa is motivated both by a personal desire to seek justice for oppressed people, and a sense that disturbing international examples of prejudice remind her of the narrow-mindedness she witnesses in her own school and community. Her identity as a member of the dominant culture of a rather homogeneous white community has perhaps played a role in building her confidence to continue with activist efforts in the face of administrative resistance and peer apathy. She seems encouraged by her modest initial efforts and genuinely committed to continuing her activism beyond school.

Sina has already been in contact with student members of STOP through an organized cultural diversity leadership camp they attended together during the previous year. Using the Internet, she and her schoolmates maintain a personal connection with other student activists hundreds of kilometers away: "We've been talking to them. We all chat on-line so we often talk about the stuff we're doing in our schools. The two of us who are in charge talk to them all the time and we get suggestions and stuff."

Some of the student members of STOP have demonstrated a high degree of computer literacy, and regularly design and modify their own web sites, take part in chat groups, and search the Internet for social action information and related contacts. STOP's recent appearance on an internationally known rock group's web site has brought communication from dozens of young people from around the world, who have sought further information and collaboration with our students. Many young activists seem very comfortable with computers and with the medium of cyberspace as additional tools in their collective struggle for social justice.

Other students working in activist groups in this area show themselves to be interested in developing in-school partnerships to help them achieve their goals to promote diversity and challenge racism. Sina talks about some possible links for her new group to explore within her school, recognizing that these kinds of collaborations can begin to forge important links within the school community and build on the strengths of others to move toward common or overlapping goals: 
In our school we have a drama club and the choral people. We've also talked to them and they're interested in talking about STOP and stuff and doing little skits about issues that we would like. Because we don't have any money in [our program] either, we thought maybe we'd charge a dollar and the drama people could do a little skit about it. Then we'd make money and we could give the drama department some and then everyone would be happy.

Sina says she is inspired by her activist work in school and plans to go to university after high school and continue her work in intercultural understanding:

I was thinking I'd go overseas and just help people there, but I don't know exactly how. Maybe I'd teach them English or something, like with the Aga Khan Foundation. I want to join that, and go overseas and help all those people who don't have the opportunities we do. I was thinking of doing that for a couple of years and then coming back and then doing something else, like international development. I'm not sure yet though.

Though her notions of working in less-developed nations are still somewhat broad, Sina seems realistic in her aspirations. She has a specific organization in mind that has had success in setting up educational institutions in a variety of nations. Her interest and experience in her diverse high school is likely to aid her progress toward this goal. Her identity as an Indo-Canadian female has shaped her notions of social justice, as she indicates by her frank discussions of the racism she has faced.

Likewise, Sabrina says, "I'd just really like to still be involved with Amnesty International in the future. They are effective in what they can do, they have a lot of money, and are involved in so many things." Her involvement as a student with the well-organized international human rights group has been brought about because of the activist group she and her sister formed in their high school. She believes her rocky experiences with fund-raising for Amnesty International and planning events that have been less than successful have helped her develop a greater empathy for social causes.

Sabrina explains, "We've had some experience trying to organize something and seen the apathy out there, so we're not likely to turn down another organization that may need our support." As she and her sister, 
Ramona, have found with their own activist work, "Once you see this sort of thing happening you can't really stop and close your eyes and say, 'I don't know about that sort of thing' anymore." And, as others in this field have observed, Ramona notes cynically that, " $80 \%$ of the volunteering is done by the same people. There are some people who volunteer a whole lot, some just a little, and a whole bunch who don't." Their discouragement about the apathy they see in so many of their peers is inevitably filtered by the ongoing nature of their personal experiences as Asian-Canadians living in a predominantly white urban centre. For these two sisters, the issues of racism and social injustice cannot simply be "put on the back burner" for a more convenient time, but remain pressing and lived aspects of their lives in western Canada.

The cooperation that comes from joining others in the same cause can be very rewarding, especially in this field where the issues that arise can be very sensitive and painful at times. Working with like-minded peers can remind activists that they are not alone in the struggle for fairness, and that, sometimes, voices can be better heard when they join together in a chorus (SooHoo, 1995). Ramona expresses her views about the other activist students she has found in her school: "It's nice to be in a group of people who are all active, who all believe the same things, and who are all working toward the same goals. It's very positive."

Daria is a student activist who says she has found her involvement with an educational coalition to challenge discrimination to be an important part of her identity in many ways. She explains that she had already experienced racism since immigrating to Canada from a South American country, and was eager to work against it:

I remember at a very young age, I was seven at the time, that we did experience racism. I remember walking with my dad back to the home where we were staying and there were I think a couple of teenagers pointing and laughing and saying "Indian, Indian" and I know that there is quite a lot of discrimination against the Aboriginal people, and so we were mistaken as Aboriginal people with our dark hair. My father is dark-skinned and so are my two brothers, and my dad even told us that two blocks from our home there was a man who used to hang a Nazi flag on his window. So growing up in that racist-I'm not going to call the whole community racistbut in a community with people who were racist made it a real personal issue for me. 
Daria says that, in the years since this difficult time, she has not seen racism against her family disappear, even as they learned English and attempted to assimilate into mainstream Canadian society:

Even now, here in [a large city], my mother has a hard time finding a job. She has two degrees in nursing and got one of the highest scores in the [English proficiency] exam in the year that she wrote it. Yet when she was interviewed for a position in nursing, she was told that she would have to go and take an English course. They said that they felt that her accent would interfere with her ability to perform the job well. And I thought that that, in itself, was quite racist, seeing as how my mom does speak fluent English. She does have an accent as do many other people in the nursing field and that does not disable them from performing their jobs.

It is significant that she names such discrimination against people who speak with an accent as "racist," substantially dependent on the skin colour of the person with the accent. Daria also makes a direct link between her family's personal experiences with racism and her own enthusiasm for challenging it in an activist coalition with other young people:

Within my family there has been a lot of experience with racism, so it's a personal issue for me. That's why I think I've been able to stick with it, and to want to keep active. I'm pretty passionate about it, and when I read something in the [newspaper], whether it be anti-Semitism or a racist incident, blatant or even subtle, I take it too hard and I want people to hear about it.

Daria believes that her personal experience with racism both stimulates her interest and provides a distinct advantage to her when speaking to others about the topic:

I think when you experience something and it has degraded you in some way, speaking from experience, that you can relate to victims of racism better than someone who has not experienced racism. It's easier to connect with the crowd when you share your experiences. I also think that just the 
fact that you want to prevent another person from going through what you went through, that's a big driving force.

Her involvement with the activist group has, in turn, encouraged her in many ways to continue to cooperate with other young people in the struggle to eliminate racism and other forms of discrimination. She has reaped several benefits, including becoming a person who is more likely to challenge her own prejudices. She explains:

What I do to try to fight that within myself, especially because I am in an antiracist organization, is that, in order to be a good example to others in the position I'm in now, in order to fight these prejudices with myself, I try to interact with groups that I feel I may have a prejudice against. Whether it be someone who dresses up as a "goth" or someone who is Lebanese, for example, I think that's a way of fighting these internal feelings of racism or prejudice that we may have. When you try to develop understanding and compassion towards a certain group then you begin to eliminate fear and ignorance.

As she has shown in other parts of the interview, Daria does not naively believe that her personal attitudes are the only-nor the most damagingform of racism in Canada, but she targets her own behaviour and values as an important starting point for becoming sensitized and working against all racism.

When asked about the future of her group, Daria is optimistic that its individual members have enough commitment to continue their work in the coming years even if the group comes apart as its members go off to various post-secondary institutions. She believes that high school graduation will likely be a "big blow" to the group but by no means the end of it:

The upside is that perhaps we could all go off to different provinces or different countries and start our own [activist group] within that community. Knowing how committed the members are, and how passionate we've grown to be towards the issue, I don't think that it will fall apart. We need to make sure that we have a huge discussion about this and plan.

Not content to leave things to chance, Daria and her colleagues will be taking proactive steps to ensure that they each continue the work they have begun in their voluntary coalition. 
Setting a strong example for her peers, Daria is already planning to pursue a medical career and join Doctors Without Borders, to "incorporate medicine with social activism." She brings it back to her high school activist work once again: "Just being involved with [our activist group] and doing the humanitarian work has inspired me to pursue that for a job." She seems certain of her continued desire to struggle for social justice, in yet another example of the youthful optimism that fuels this endeavour. Further, her self-identification as a non-white Canadian also seems to drive Daria's single-minded commitment to a career that includes social justice activism.

Steve and Jason share with me that they are often approached by community groups to collaborate on projects, but they are reluctant to be "taken under the wing" of a larger organization, preferring instead to be members of an independent, student-led group. Jason says that, "right now we have lots of contacts with people who are more than willing to give us resources." When I ask for an example, Jason shares that a new antiracist group in their city "has just offered our group some money" but that their student group will need more information about how it fits with their own goals before accepting it. Steve concedes that their group is "still very young and we're still trying to find our way, and this whole government funding thing, you know, we're cautious." Their independence and caution regarding their group's access to resources may be tied to their identity as white males. Although they do not say so directly, their leadership roles in the group provide strategic advantages based on their positions of gendered and racialized privilege. Of course, generalizing about all white people is dangerous and counterproductive to the goals of social justice pedagogy; as Kincheloe and Steinberg (2000) remind us, "it is not contradictory to argue that whiteness is a marker of privilege but all white people are not able to take advantage of that privilege" (p. 182).

Not every student who engages in social justice activism in high school will continue with these pursuits in future. Many students do not consider their high school activist experience as a springboard for future careers and advantages. Steve explains that, "for a lot of us, it's something we want to do because we want to do it now. It's not something that we want to use as a jumping point to any other fields." In fact, says Jason, after graduating high school, "If I had absolutely no ties to bind me, I'd go to the coast and jump on an oil ship and go wherever the winds take me!" Nonetheless, they note that several of their current group members are interested in careers in politics, with at least one wanting to be an international ambassador, and that their involvement with the group will inevitably provide them with some advantages in pursuing these goals. No doubt their identity markers of privilege have also shown them in both subtle and overt ways that they need not worry too much about their own future employment opportunities in this country. 


\section{Conclusion}

As the researcher has experienced with other student activists, and these respondents have corroborated, students engaged in school coalitions seem likely to extend their engagement with social justice issues beyond their school's walls. Their development of crucial cooperative and planning skills, their learning about complex diversity issues, and their experience with organizing a range of activities to promote social justice may all serve to foster further activism. Their differential experiences with racism and other discrimination also play a role in shaping each of their perspectives on social justice work.

Both Jason and Steve reveal evidence of strong success in coalitionbuilding among their peers, and in accessing the kinds of government and community resources their group might need in fulfilling its goals. Their lighthearted notions of commitment to social justice activism, and their confidence in finding support for their work and future employment, are probably fostered to a large extent by their unspoken, learned privilege as white males in an inequitable society. The ongoing project of understanding and dismantling white privilege continues, informed by recent scholarship (e.g., Rodriquez \& Villaverde, 2000). Also, the more limited offerings on this topic in general by these male participants are worth noting here. With their female counterparts more willing to explore issues of collaboration and cooperation toward overlapping goals, this research suggests that the gendered nature of social justice work offers a rich possible field for further inquiry.

In a related example, Sabrina and her sister Ramona both sought the solidarity of their like-minded peers in the face of widespread apathy in their school on issues of human rights. Their establishing of volunteer activist groups provided them with a meaningful way of finding solidarity on issues of social justice, and building on the foundation of other established groups such as Amnesty International. Similarly, Sina found her engagement with fellow high school students at a provincial youth leadership camp helped her establish links among committed school activists. They used the Internet and other computer pathways with great ease to establish an informal network of students interested in promoting diversity and challenging racism, and thus demonstrated that young activists have much to contribute to our growing understanding of the myriad possibilities for networking across diverse groups and communities.

Sina also sought links with established clubs and programs already

existing in her school. Like our STOP program and other groups with whom we have worked, this networking with existing school bodies provides important solidarity in the school-wide efforts toward progressive social change. Sina 
also planned to further her education after high school both through formal post-secondary education and travel, and wished to work toward international development. Likewise, Daria had already planned an ambitious medical career that would combine her interests in social justice and medicine, namely by joining Doctors Without Borders.

The strong notions of future commitment to equity in the careers and community activism of these particular young women have been shaped by their socially ascribed roles as members of non-white ethnic groups in Canada; the discrepancy between their definite goals and those expressed by the young white males in this study suggests a promising direction for further research and analysis. Further, critical educators must continue the struggle to help white students understand the complexities of privilege, unlearn racism, and collaboratively "develop antiracist policies and progressive ways of being white" (Kincheloe \& Steinberg, 2000, p. 194).

Inevitably, the building of bridges among activists and activist groups goes beyond the school walls. As Fullan (1999) reminds us, "by extending purposeful alliances to diverse outside partners we gain moral meaning in educational reform and contribute to its spread" (p. 60). The activist coalitions that form in schools are another vehicle for those already committed to these issues, but for many others, they provide a valuable jumping-off point for a lifelong commitment to fairness and equity. Educators and educational researchers alike need to consider effective ways of working collaboratively and respectfully with school activists to better understand and sustain meaningful opportunities for social change.

The rich offerings from the student participants in this research provide another chorus of voices that can complement those already being heard in academic research and theorizing. Views on their struggles and successes, and other insights from these young activists on working cooperatively in school projects, offer abundant evidence of their previously undervalued role as crucial participants in educational programming for diversity, school reform efforts, and research toward social justice.

\section{Author's Note}

The author gratefully acknowledges research funding for this study from the Social Sciences and Humanities Research Council, the Alberta Teachers' Association, and the Killam Trusts. 
D. E. Lund

\section{References}

Alberta Human Rights and Citizenship Commission. (2000, May). Tools for transformation: Human rights education and diversity initiatives in Alberta. Edmonton, AB: Government of Alberta.

Berlin, M. L., \& Alladin, M. I. (1996). The Kipling Collegiate Institute story: Towards positive race relations in the school. In M. I. Alladin (Ed.), Racism in Canadian schools (pp. 131-146). Toronto, ON: Harcourt Brace.

Canadian Race Relations Foundation. (2001). CRRF 2001 Best practices reader. Toronto, ON: Author.

Carspecken, P. F. (1996). Critical ethnography in educational research: A theoretical and practical guide. New York: Routledge.

Dei, G. J. S., James, I. M., James-Wilson, S., Karumanchery, L. L., \& Zine, J. (2000). Removing the margins: The challenges and possibilities of inclusive schooling. Toronto, ON: Canadian Scholars' Press.

Foster, M. (1993). Self-portraits of Black teachers: Narratives of individual and collective struggle against racism. In D. McLaughlin \& W. G. Tierney (Eds.), Naming silenced lives: Personal narratives and the process of educational change (pp. 155-175). New York: Routledge.

Fullan, M. (1999). Change forces: The sequel. Philadelphia, PA: Falmer Press.

Giroux, H. A. (1996). Fugitive cultures: Race, violence, and youth. New York: Routledge.

Hall, S. (1992). New ethnicities. In J. Donald \& A. Rattansi (Eds.), 'Race', culture, and difference (pp. 252-259). London, UK: Sage.

Kielburger, C., \& Major, K. (1998). Free the children. Toronto, ON: McClelland \& Stewart.

Kincheloe, J. L., \& Steinberg, S. R. (2000). Constructing a pedagogy of whiteness for angry white students. In N. M. Rodriquez \& L. E. Villaverde (Eds.), Dismantling white privilege: Pedagogy, politics, and whiteness (pp. 178-194). New York: Peter Lang.

Kinsella, W. (2001). Web of hate: Inside Canada's far right network ( $2^{\text {nd }}$ ed.). Toronto, ON: Harper Collins.

Lund, D. E. (1998). Social justice activism in a conservative climate: Students and teachers challenging discrimination in Alberta. Our Schools/Our Selves, 9(4), 24-38.

Lund, D. E. (2001). Social justice pedagogy and teacher-student activism: A collaborative study of school-based projects. Unpublished doctoral dissertation, University of British Columbia, Vancouver, B.C. 
Lund, D. E. (in press). Rising to the challenge: Student antiracist activists counter backlash and stereotyping. Teaching Education Journal.

Marshall, C., \& Rossman, G. B. (1995). Designing qualitative research (2nd ed.). Thousand Oaks, CA: Sage.

$\mathrm{Ng}$, R. (2003). Toward an integrative approach to equity in education. In P. P. Trifonas (Ed.), Pedagogies of difference: Rethinking education for social change (pp. 206-219). New York: Routledge Falmer.

Rodriquez, N. M., \& Villaverde, L. E. (Eds.). (2000). Dismantling white privilege: Pedagogy, politics, and whiteness. New York: Peter Lang.

Smith, J., \& Young, J. (1996). Building an anti-racist school: The story of Victor Magel School. In K. A. McLeod (Ed.), Multicultural education: The state of the art national study, Report \#4 (pp. 57-66). Winnipeg, MB: Canadian Association of Second Language Teachers.

SooHoo, S. (1995). Emerging student and teacher voices: A syncopated rhythm in public education. In B. Kanpol \& P. McLaren (Eds.), Critical multiculturalism: Uncommon voices in a common struggle (pp. 217234). Westport, CT: Bergin \& Garvey. 